\title{
Heterosis for biomass yield and related traits in five hybrids of Arabidopsis thaliana L. Heynh
}

\author{
S Barth ${ }^{1}$, AK Busimi, H Friedrich Utz and AE Melchinger \\ Institute of Plant Breeding, Seed Science and Population Genetics, University of Hohenheim, Fruwirthstraße 21, D-70599 Stuttgart, \\ Germany
}

\begin{abstract}
Heterosis is of utmost economic importance in plant breeding. However, its underlying molecular causes are still unknown. Given the numerous advantages of Arabidopsis thaliana as a model species in plant genetics and genomics, we assessed the extent of heterosis in this species using five hybrids derived from five ecotypes. Parents, $F_{1}$ and $F_{2}$, generations in both reciprocal forms were grown in a greenhouse experiment with four replications. Mid-parent heterosis (MPH) and best-parent heterosis $(\mathrm{BPH})$ averaged across hybrids were surprisingly high for biomass yield (MPH: 60.3\%; BPH: 32.9\%) and rosette diameter (MPH:
\end{abstract}

49.4\%; BPH: 34.8\%), but smaller for flowering date (MPH: 27.5\%; $\mathrm{BPH}: 18.5 \%)$, seed yield (MPH: 18.9\%; $\mathrm{BPH}: 1.7 \%)$, and yield components. Individual hybrids varied considerably in their $\mathrm{MPH}$ and $\mathrm{BPH}$ values for all traits, one cross displaying $140.1 \% \mathrm{MPH}$ for biomass yield. MPH was not associated with parental genetic distance determined from molecular markers. Reciprocal effects were significant only in a few cases. With a proper choice of hybrids, our results encourage the use of Arabidopsis as a model species for investigating the molecular causes of heterosis.

Heredity (2003) 91, 36-42. doi:10.1038/sj.hdy.6800276

Keywords: heterosis; Arabidopsis thaliana; reciprocal effects; genetic distances

\section{Introduction}

Shull (1914) coined the term heterosis to describe the improved vigour of $\mathrm{F}_{1}$ hybrids in comparison to their parental homozygous lines. Since its discovery in the last century (East, 1908; Shull, 1908), it is a widely used yet little understood phenomenon in plant breeding (Schnell, 1982). In general, heterosis is largest in allogamous plants, which are, however, also the most sensitive to inbreeding depression, and heterosis is smallest in strictly autogamous species (Becker, 1993). Furthermore, the relative amount of heterosis increases with the complexity of a trait. A better understanding of heterosis is crucial for agronomically important characters such as biomass and seed yield.

The molecular basis of heterosis is still unknown. Genetic explanations include dominance, overdominance, and epistasis (for review, see Lamkey and Edwards, 1999). With two alleles per locus and no epistasis, heterosis is theoretically a quadratic function of the parental genetic distance (GD) at the underlying quantitative trait loci (QTL) for the trait considered (Falconer and Mackay, 1996; Melchinger, 1999). Experiments with maize showed an increase in heterosis with increasing parental GD (Moll et al, 1962; Melchinger, 1999), but they also suggested an optimum level of parental GD, after which heterosis and hybrid performance decline (Moll et al, 1965).

Correspondence: AE Melchinger. Institute of Plant Breeding, Seed Science and Population Genetics, University of Hohenheim, Fruwirthstraße 21, D-70599, Stuttgart, Germany. E-mail: melchinger@uni-hohenheim.de ${ }^{1}$ Current address: Teagasc, Crops Research Centre Oak Park, Carlow, Ireland

Received 1 August 2002; accepted 18 February 2003
A better understanding of the biological mechanisms underlying heterosis should lead to more systematic approaches in the identification of suitable parent matches for superior hybrids. Recent improvements in tools for plant functional genomic analysis, for example, expression profiling of parental lines and their hybrids for mRNA, proteins, or metabolites, in conjunction with the use of the well-characterized and fully sequenced genetic model plant Arabidopsis thaliana have opened new avenues for investigating the basis of heterosis (Somerville and Somerville, 1999). The Arabidopsis functional genomics project (The Multinational Arabidopsis Steering Committee, 2002) defined, as a longterm goal for 2010, the study of complex genetic networks, which includes the systematic investigation of heterosis.

In Arabidopsis, only a few traits of agronomic interest have been investigated so far with respect to heterosis, among them rosette diameter (El Asmi, 1975), stem length and biomass yield (Griffing and Langridge, 1963; Li and Rédei, 1969), number of seeds per plant (Alonso-Blanco et al, 1999), as well as phosphate acquisition efficiency (Narang and Altmann, 2001). However, most of these studies were limited in their informative value in that they employed only a few hybrids, or involved mutants as parents. QTL mapping for general viability of seedlings has been used to identify a chromosomal region showing overdominance as an explanation for heterosis in this trait (Mitchell-Olds, 1995).

Since information on heterosis for agronomically relevant traits is rather scant in Arabidopsis, more extensive experiments with additional traits are urgently needed before initiating genomics research programs on 
the causes of heterosis. The objectives of the present study were to

(1) determine the general level of mid-parent (MPH) and best-parent heterosis (BPH) in A. thaliana for traits of agronomic interest in order to answer the question of whether this autogamous species represents a suitable model for investigating the molecular basis of heterosis,

(2) measure the variation in the amount of $\mathrm{MPH}$ and $\mathrm{BPH}$ among different hybrids of Arabidopsis,

(3) monitor for reciprocal effects in the $F_{1}$ and $F_{2}$ generations, and

(4) assess the association between genetic distance and $\mathrm{MPH}$.

\section{Materials and methods}

\section{Plant materials}

The ecotypes used in this study (Col- 0 , Ws-2, Wei-0, Aa$0, \mathrm{C} 24)$ and their origins were described in detail by Barth et al (2002). Ecotypes were sown on 21 March, 2000. Seeds were grown as described by Barth et al (2000). At the four-leaf stage, approximately 10-11 days after sowing, each seedling was transferred to an individual jiffy pot $\left(7 \times 7 \times 8 \mathrm{~cm}^{3}\right)$ filled with sterilized soil (Euflor GmbH: $90 \%$ peat, $7 \%$ perlite and 3 vol \% sand at $\mathrm{pH}$ of 56 , salt content $<1.5 \mathrm{~g} / 1$, nitrogen availability $<300 \mathrm{mg} / 1$ $\mathrm{N}$, phosphate availability $<300 \mathrm{mg} / 1 \mathrm{P}_{2} \mathrm{O}_{5}$, and calciumoxide availability $<400 \mathrm{mg} / 1 \mathrm{~K}_{2} \mathrm{O}$ ). Plants in soil were irrigated with tap water.

\section{Material development}

In a previous study in our lab (Barth et al, 2002), GD values calculated according to Nei and Li (1979) were determined among 37 ecotypes from molecular data based on 54 polymorphic cleaved amplified polymorphic sequences (CAPS), markers with good coverage of the entire genome. Five $F_{1}$ hybrids including reciprocals were produced based on small, medium and large GD, and synchronous flowering date of the parents: $\mathrm{C} 24 \times \mathrm{Aa}-0 \quad(\mathrm{GD}=0.32), \mathrm{C} 24 \times \mathrm{Ws}-2 \quad(\mathrm{GD}=0.46), \mathrm{Ws}-$ $2 \times$ Col-0 $(\mathrm{GD}=0.50)$, Col-0 $\times \mathrm{C} 24(\mathrm{GD}=0.53)$ and Col$0 \times$ Wei-0 $(\mathrm{GD}=0.57)$.

$\mathrm{F}_{1}$ hybrids were produced in April and May 2000. Crossing procedures were as described by Barth et al (2000). The $F_{1}$ hybrids were sown for selfing on 28 May, 2000. Siliques were harvested at maturity from five individual $\mathrm{F}_{1}$ plants per hybrid.

The materials for measurement of heterosis were grown during the winter 2000/2001 in a greenhouse at the University of Hohenheim, Stuttgart. Sowing of the parents ( $\mathrm{P} 1$ and $\mathrm{P} 2)$, as well as the $\mathrm{F}_{1}$ and $\mathrm{F}_{2}$ generations of each hybrid in both reciprocal forms, was carried out on 3 October 2000.

\section{Traits measured}

Flowering date (in days) was determined as the number of days from sowing to the appearance of inflorescence. Rosette diameter (in $\mathrm{cm}$ ) was recorded 48-50 days after sowing on a single-plant basis by measuring the longest leaves in the rosette with an accuracy of $\pm 1 \mathrm{~mm}$. After recording the rosette diameter, each plant was covered with a seed collector (ARACONS, Beta tech bvba). All plants of a subplot, including the siliques but without the root system, were bulked and harvested after senescence into glass jars. Biomass yield (in g) was recorded after drying in an oven to practically zero per cent moisture content. Seed yield (in g) was determined from dried plants, which were hand threshed and passed through a $400 \mu \mathrm{m}$ sieve (Retsch $\mathrm{GmbH}$ ) for a minimum of three times for seed purification. 1000-seed weight (in $\mathrm{mg}$ ) was determined from three samples of 100 seeds from each entry counted under a microscope. Number of seeds per plant $\left(10^{3}\right.$ seeds) was calculated by dividing total seed yield by 1000 -seed weight.

\section{Experimental design and statistical analyses}

The experimental design was a split plot (Snedecor and Cochran, 1980) with main plots and sub plots treated as fixed factors. Main plots comprised the five hybrids and were arranged in a randomized complete block design with four replications. The generations (P1 and P2 as duplicate entries; $F_{1}, F_{2}$ in both reciprocal forms each as single entries) were randomly assigned to the subplots within main plots. Each subplot consisted of five plants.

Analyses of variance (ANOVA) were performed with the parental and hybrid generations $\left(F_{1}, F_{2}\right)$ separately, owing to significant heterogeneity of errors for most traits. Statistical analyses were performed by PLABSTAT (Utz, 1999). The following contrasts were tested with appropriate two-tailed $t$-tests (Snedecor and Cochran, 1980):

absolute MPH: $\mathrm{AMPH}=\overline{F_{1}}-\bar{P}$

absolute $\mathrm{BPH}: \quad \mathrm{ABPH}=\overline{F_{1}}-P_{\max }$

nonlinearity of inbreeding: $\quad$ NLID $=\overline{F_{1}}+\bar{P}-2 \overline{F_{2}}$,

reciprocal effect in $\mathrm{F}_{1}$ : $\operatorname{Rec}\left(\mathrm{F}_{1}\right)=(\mathrm{P} 1 \times \mathrm{P} 2)-(\mathrm{P} 2 \times \mathrm{P} 1)$

reciprocal effect in $\mathrm{F}_{2}: \operatorname{Rec}\left(\mathrm{F}_{2}\right)=(\mathrm{P} 1 \times \mathrm{P} 2)^{\mathrm{s}}-$ $(\mathrm{P} 2 \times \mathrm{P} 1)^{\mathrm{s}}$ with $\bar{P}=(\mathrm{P} 1+\mathrm{P} 2) / 2 ; \overline{F_{1}}=[(\mathrm{P} 1 \times \mathrm{P} 2)+(\mathrm{P} 2 \times \mathrm{P} 1)] /$ $2 ; \overline{F_{2}}=\left[(\mathrm{P} 1 \times \mathrm{P} 2)^{\mathrm{s}}+(\mathrm{P} 2 \times \mathrm{P} 1)^{\mathrm{s}}\right] / 2$ and the superior $\mathrm{s}$ indicating selfing. In addition, we calculated the relative $\mathrm{MPH}$ as $\mathrm{MPH}=100 \times\left(\overline{F_{1}}-\bar{P}\right) / \bar{P}$ and relative $\mathrm{BPH}$ as $\mathrm{BPH}=100 \times\left(\overline{F_{1}}-P_{\max }\right) / P_{\max }$ where $P_{\max }$ refers to the higher performing parent.

\section{Results}

In general, the parents of each hybrid differed significantly $(P<0.05)$ from each other for all traits (data not shown). Exceptions were found for parents in C24 $\times$ Aa-0 for rosette diameter, biomass yield, seed yield, and 1000seed weight, in Ws- $2 \times$ Col- 0 for seed yield and in Col-0 $\times \mathrm{C} 24$ for all traits related to seed yield. MPH averaged across hybrids was highly significant for all five traits $(P<0.01)$ (Table 1). BPH, however, was not significant for seed yield and number of seeds per plant. Mean $\mathrm{MPH}$ was surprisingly high for biomass yield (60.3\%) and rosette diameter $(49.4 \%)$, but below $30 \%$ for the other traits. However, a large amount of variation for $\mathrm{MPH}$ existed among the five hybrids for all traits. Averaged across hybrids, the test for nonlinearity of inbreeding depression (NLID) in the three generations $\left(\bar{P}, \overline{F_{1}}, \overline{F_{2}}\right)$ was not significant $(P<0.05)$ for all traits (data not shown).

For flowering date, the overall mean of the parental generation differed significantly from both the $\mathrm{F}_{1}$ and $\mathrm{F}_{2}$ generations. MPH amounted to $27.5 \%$ and $\mathrm{BPH}$ to $18.5 \%$ (Table 1). In all crosses involving $\mathrm{C} 24$ as a parent, the $\mathrm{F}_{1}$ and $F_{2}$ generations flowered 10-15 days later than $\bar{P}$ with $\mathrm{MPH}$ ranging between 33.8 and $58.9 \%$. In the other two 
Table 1 Mid-parent value $(\bar{P}=(\mathrm{P} 1+\mathrm{P} 2) / 2)$, and performance of generations $\mathrm{F}_{1}$ and $\mathrm{F}_{2}$ averaged over both reciprocal forms $\left(\overline{F_{1}}, \overline{F_{2}}\right)$ as well as relative mid-parent heterosis $(\mathrm{MPH})$ and best-parent heterosis (BPH) for six traits in five hybrids of $A$. thaliana

\begin{tabular}{|c|c|c|c|c|c|c|}
\hline \multirow[t]{2}{*}{ Generation } & \multicolumn{5}{|c|}{ Hybrid } & \multirow[b]{2}{*}{ Mean } \\
\hline & $\mathrm{C} 24 \times A a-0$ & $C 24 \times W s-2$ & Ws $-2 \times$ Col- 0 & Col- $0 \times$ C24 & Col-0 $\times$ Wei-0 & \\
\hline \multicolumn{7}{|c|}{ Flowering date (days) } \\
\hline $\bar{P}$ & $29.5^{\mathrm{a}}$ & $27.6^{\mathrm{a}}$ & $24.9^{\mathrm{a}}$ & $29.6^{\mathrm{a}}$ & $25.4^{\mathrm{a}}$ & $27.4^{\mathrm{a}}$ \\
\hline$\overline{F_{1}}$ & $44.8^{\mathrm{b}}$ & $37.0^{\mathrm{b}}$ & $23.8^{\mathrm{a}}$ & $47.0^{\mathrm{b}}$ & $24.7^{\mathrm{a}}$ & $35.5^{\mathrm{b}}$ \\
\hline$\overline{F_{2}}$ & $42.1^{\mathrm{b}}$ & $39.3^{\mathrm{b}}$ & $25.8^{\mathrm{a}}$ & $38.7^{\mathrm{b}}$ & $26.3^{a}$ & $34.4^{\mathrm{b}}$ \\
\hline $\mathrm{MPH}^{\mathrm{d}}$ & $52.0^{* *}$ & $33.8^{* *}$ & -4.4 & $58.9^{* *}$ & -2.7 & $27.5^{* *}$ \\
\hline $\mathrm{BPH}^{\mathrm{e}}$ & $43.9^{* *}$ & $15.7^{* *}$ & -9.2 & $48.0^{* *}$ & -6.2 & $18.5^{* *}$ \\
\hline \multicolumn{7}{|c|}{ Rosette diameter $(\mathrm{cm})$} \\
\hline $\bar{P}$ & $6.97^{\mathrm{a}}$ & $7.64^{\mathrm{a}}$ & $6.88^{\mathrm{a}}$ & $8.68^{\mathrm{a}}$ & $8.20^{\mathrm{a}}$ & $7.67^{\mathrm{a}}$ \\
\hline$\overline{F_{1}}$ & $12.33^{\mathrm{b}}$ & $14.07^{\mathrm{b}}$ & $7.02^{\mathrm{a}}$ & $14.69^{\mathrm{b}}$ & $9.39^{\mathrm{b}}$ & $11.50^{\mathrm{b}}$ \\
\hline$\overline{F_{2}}$ & $11.26^{\mathrm{b}}$ & $10.43^{c}$ & $8.04^{\mathrm{a}}$ & $10.69^{c}$ & $9.04^{\mathrm{b}}$ & $9.90^{c}$ \\
\hline $\mathrm{MPH}^{\mathrm{d}}$ & $76.9^{* *}$ & $84.2^{* *}$ & 2.1 & $69.2^{* *}$ & $14.5^{* *}$ & $49.4^{* *}$ \\
\hline $\mathrm{BPH}^{\mathrm{e}}$ & $72.2^{* *}$ & $48.4^{* *}$ & -10.1 & $60.7^{* *}$ & 2.6 & $34.8^{* *}$ \\
\hline \multicolumn{7}{|c|}{ Biomass yield (g per 10 plants) } \\
\hline $\bar{P}$ & $4.31^{\mathrm{a}}$ & $8.15^{\mathrm{a}}$ & $7.49^{a}$ & $6.99^{a}$ & $6.73^{\mathrm{a}}$ & $6.74^{\mathrm{a}}$ \\
\hline$\overline{F_{1}}$ & $10.35^{\mathrm{b}}$ & $12.61^{\mathrm{b}}$ & $7.88^{\mathrm{a}}$ & $11.21^{\mathrm{b}}$ & $9.51^{\mathrm{b}}$ & $10.31^{\mathrm{b}}$ \\
\hline$\overline{F_{2}}$ & $10.27^{b}$ & $7.62^{\mathrm{a}}$ & $8.56^{\mathrm{a}}$ & $6.82^{\mathrm{a}}$ & $7.93^{\mathrm{b}}$ & $8.24^{c}$ \\
\hline $\mathrm{MPH}^{\mathrm{d}}$ & $140.1^{* *}$ & $54.7^{* *}$ & 5.2 & $60.4^{* *}$ & $41.3^{* *}$ & $60.3^{* *}$ \\
\hline $\mathrm{BPH}^{\mathrm{e}}$ & $121.6^{* *}$ & 6.0 & -9.7 & $41.4^{* *}$ & 5.2 & $32.9^{* *}$ \\
\hline \multicolumn{7}{|c|}{ Seed yield (g per 10 plants) } \\
\hline $\bar{P}$ & $1.48^{\mathrm{a}}$ & $2.93^{a}$ & $2.30^{\mathrm{a}}$ & $2.28^{a}$ & $2.10^{\mathrm{a}}$ & $2.22^{\mathrm{a}}$ \\
\hline$\overline{F_{1}}$ & $1.87^{\mathrm{a}}$ & $3.25^{\mathrm{a}}$ & $2.77^{\mathrm{b}}$ & $1.62^{\mathrm{b}}$ & $3.48^{\mathrm{b}}$ & $2.60^{\mathrm{b}}$ \\
\hline$\overline{F_{2}}$ & $2.17^{\mathrm{a}}$ & $1.95^{\mathrm{b}}$ & $2.82^{\mathrm{b}}$ & $1.67^{\mathrm{b}}$ & $2.71^{\mathrm{c}}$ & $2.26^{\mathrm{a}}$ \\
\hline $\mathrm{MPH}^{\mathrm{d}}$ & 26.4 & 10.9 & $20.4^{*}$ & $-29.0^{* *}$ & $65.7^{* *}$ & $18.9^{* *}$ \\
\hline $\mathrm{BPH}^{\mathrm{e}}$ & 12.0 & $-21.5^{* *}$ & 17.9 & $-34.7^{* *}$ & $34.9^{* *}$ & 1.7 \\
\hline \multicolumn{7}{|c|}{ 1000-seed weight (mg) } \\
\hline $\bar{P}$ & $18.1^{\mathrm{a}}$ & $18.1^{\mathrm{a}}$ & $21.6^{\mathrm{a}}$ & $20.1^{\mathrm{a}}$ & $21.8^{\mathrm{a}}$ & $19.9^{\mathrm{a}}$ \\
\hline$\overline{F_{1}}$ & $20.9^{\mathrm{b}}$ & $18.6^{\mathrm{a}}$ & $16.8^{\mathrm{b}}$ & $19.3^{\mathrm{b}}$ & $18.4^{\mathrm{b}}$ & $18.8^{\mathrm{b}}$ \\
\hline$\frac{1}{F_{2}}$ & $20.3^{\mathrm{b}}$ & $18.6^{\mathrm{a}}$ & $18.4^{\mathrm{b}}$ & $20.3^{\mathrm{b}}$ & $19.0^{\mathrm{b}}$ & $19.3^{\mathrm{b}}$ \\
\hline $\mathrm{MPH}^{\mathrm{d}}$ & $15.5^{* *}$ & 2.8 & $-22.2^{* *}$ & -4.0 & $-15.6^{* *}$ & $-4.7^{* *}$ \\
\hline $\mathrm{BPH}^{\mathrm{e}}$ & 10.6 & -6.9 & $-33.7^{* *}$ & -5.5 & $-19.7^{* *}$ & $-11.0^{* *}$ \\
\hline \multicolumn{7}{|c|}{ No. seeds per plant $\left(10^{3}\right)$} \\
\hline $\bar{P}$ & $7.85^{\mathrm{a}}$ & $15.89^{a}$ & $11.09^{a}$ & $11.26^{\mathrm{a}}$ & $9.46^{\mathrm{a}}$ & $11.11^{\mathrm{a}}$ \\
\hline$\overline{F_{1}}$ & $8.88^{\mathrm{a}}$ & $18.28^{\mathrm{a}}$ & $15.91^{\mathrm{b}}$ & $9.12^{\mathrm{a}}$ & $18.39^{\mathrm{b}}$ & $14.12^{\mathrm{b}}$ \\
\hline$\overline{F_{2}}$ & $10.17^{a}$ & $9.24^{\mathrm{b}}$ & $15.27^{\mathrm{b}}$ & $7.72^{\mathrm{a}}$ & $14.34^{c}$ & $11.35^{\mathrm{a}}$ \\
\hline $\mathrm{MPH}^{\mathrm{d}}$ & 13.1 & 15.0 & $43.5^{* *}$ & -19.0 & $94.4^{* *}$ & $29.4^{* *}$ \\
\hline $\mathrm{BPH}^{\mathrm{e}}$ & -4.8 & -12.8 & 20.8 & $-25.9^{*}$ & $66.0^{* *}$ & 8.6 \\
\hline
\end{tabular}

*** significant at $P=0.05$ and 0.01 , respectively.

a, b, c Generation means $\left(\overline{P_{1}}, \overline{F_{1}}, \overline{F_{2}}\right)$ followed by a common letter are not significantly different at $P=0.05$ using a protected LSD.

${ }^{\mathrm{d}} \mathrm{MPH}=100 \times\left(\overline{F_{1}}-\bar{P}\right) / \bar{P}$, but the significance test refers to absolute mid-parent heterosis (AMPH).

eBPH=100 $\times\left(\overline{F_{1}}-P_{\max }\right) / P_{\max }$, where $P_{\max }$ refers to the higher performing parent and the significance test refers to absolute best-parent heterosis $(\mathrm{ABPH})$.

hybrids (Ws- $2 \times$ Col-0, Col-0 $\times$ Wei-0), MPH was not significant.

For rosette diameter, $\overline{F_{1}}$ significantly $(P<0.05)$ exceeded $\bar{P}$ with intermediate values for $\overline{F_{2}}$ except for hybrid Ws-2 $\times$ Col-0 (Table 1). Four hybrids showed highly significant $(P<0.01) \mathrm{MPH}$, ranging from $14.5 \%$ in Col-0 $\times$ Wei-0 to $84.2 \%$ in C24 $\times$ Ws-2. Three of these hybrids showed also highly significant BPH values. For biomass yield, the means of all three generations $\left(\bar{P}, \overline{F_{1}}\right.$, $\left.\overline{F_{2}}\right)$ differed significantly $(P<0.05)$. Apart from hybrid Ws- $2 \times$ Col-0, MPH was significantly $(P<0.05)$ greater than zero and ranged between 41.3 and $140.1 \%$. BPH was significant for hybrids $\mathrm{C} 24 \times \mathrm{Aa}-0 \quad(121.6 \%)$ and Col-0 $\times$ C24 (41.4\%)

For seed yield, $\overline{F_{1}}$ exceeded $\bar{P}$ in hybrids Ws $-2 \times$ Col -0 , Col-0 $\times$ C24, and Col-0 $\times$ Wei-0. MPH values averaged
$18.9 \%$ except for a higher value $(65.7 \%)$ in hybrid Col-0 $\times$ Wei-0. For 1000-seed weight, all hybrids involving Col-0 as parent showed significantly $(P<0.05)$ smaller values for $\overline{F_{1}}$ than $\bar{P}$ with $\overline{F_{2}}$ being intermediate. However, the other hybrids deviated from this pattern as reflected by the varying size of $\mathrm{MPH}$, which averaged $-4.7 \%$. For number of seeds per plant, $\mathrm{MPH}$ was highly significant $(P<0.01)$ only in hybrids Col- $0 \times \mathrm{C} 24$ and Ws$2 \times$ Col-0 and averaged $29.4 \%$. For seed-yield-related traits, only hybrid Col- $0 \times$ Wei- 0 showed a significant positive BPH value.

The linear regression of $\mathrm{MPH}$ on GD values of individual hybrids was not significant $(P<0.05)$ for all traits with $R^{2}$ values below $62.7 \%$ (Figure 1). Similar results were obtained for the regression of $\mathrm{BPH}$ on GD values (data not shown). Significant $(P<0.05)$ reciprocal 


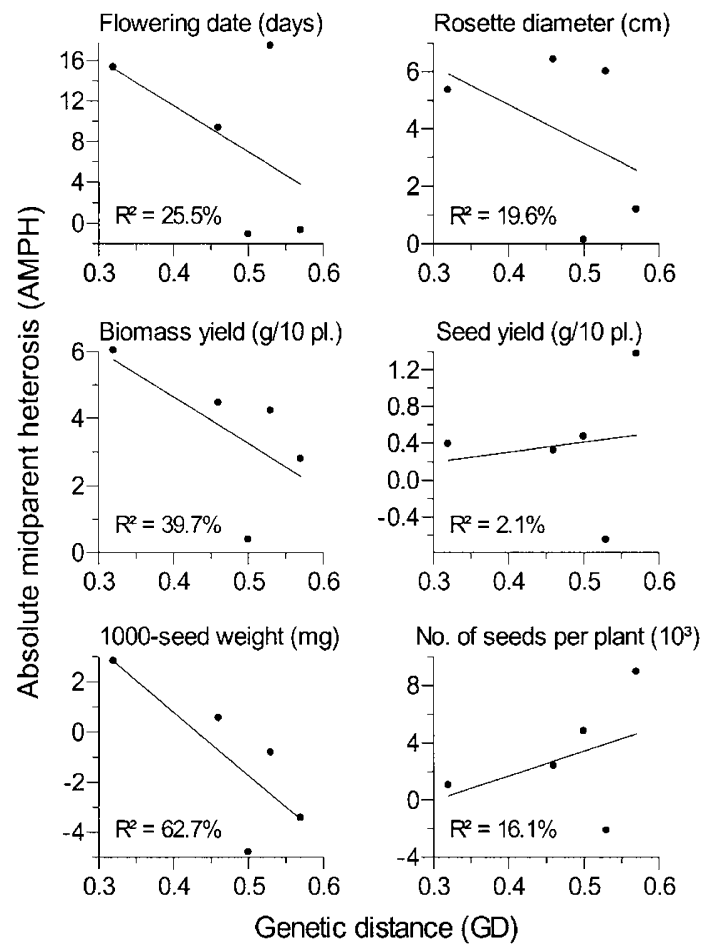

Figure 1 Graphical representation of linear regression of AMPH on GD (based on CAPS marker data) for six traits in five hybrids of $A$. thaliana: $\mathrm{C} 24 \times \mathrm{Aa}-0 \quad(\mathrm{GD}=0.32), \quad \mathrm{C} 24 \times \mathrm{Ws}-2 \quad(\mathrm{GD}=0.46)$, Ws$2 \times$ Col-0 $(\mathrm{GD}=0.50), \mathrm{Col}-0 \times \mathrm{C} 24(\mathrm{GD}=0.53)$, and Col- $0 \times$ Wei- 0 $(\mathrm{GD}=0.57)$

differences were found only for biomass and seed yield (Table 2). Reciprocal effects were generally not consistent across generations except for hybrid C24 × Ws-2, where significant reciprocal differences with identical sign were found in the $F_{1}$ and $F_{2}$ generations.

\section{Discussion}

Heterosis for different traits

In a breeding context, heterosis is often measured as $\mathrm{BPH}$, which directly reflects the superiority of hybrids over comparable line cultivars. However, with regard to quantitative-genetic theory (Falconer and Mackay, 1996), MPH has several advantages over $\mathrm{BPH}$, for example its expected quadratic relationship to the parental GD under a simple genetic model. This was the main reason for focussing our discussion on $\mathrm{MPH}$.

In general, the amount of heterosis is much smaller in autogamous than in allogamous crops (Becker, 1993; Melchinger and Gumber, 1998). In autogamous crops, a maximum MPH for seed yield of $17 \%$ for rice (Virmani, 1996) and $10 \%$ for wheat (Martin et al, 1995) was reported. Since Arabidopsis is an autogamous species with an average outcrossing rate of about $0.3 \%$ (Abbott and Gomes, 1989), we expected only a low amount of heterosis in contrast to the results observed in our study. One explanation for the high MPH in Arabidopsis could be the testing of individual plants under wide spacing, whereas field trials with crops are usually grown under high planting density and considerable interplant competition.

For flowering date, we observed a moderate positive $\mathrm{MPH}(27.5 \%)$ while Westerman (1971) found no MPH $(0.3 \%)$. This is in contrast to rice and maize, where hybrids flower earlier than their parents. Although flowering date itself does not display a high $\mathrm{MPH}$, it should be recorded in heterosis studies because it can affect other traits such as biomass and seed yield by altering the time span available for vegetative and generative growth. Pigliucci and Hayden (2001) found such a correlation between duration of vegetative phase and rosette diameter in crosses between Ler- 0 and four Arabidopsis ecotypes. However, delay of flowering date in hybrids cannot exclusively explain biomass heterosis in Arabidopsis, because Col- $0 \times$ Wei-0 displayed substantial biomass heterosis in the absence of significant differences for flowering date among generations $\mathrm{P}, \mathrm{F}_{1}$, and $\mathrm{F}_{2}$. In addition, heterosis for flowering date in Col- $0 \times \mathrm{C} 24$ and C24 $\times$ Aa- 0 were of similar size, even though the later hybrid showed about twice as much MPH for biomass yield than the former. A more precise estimation of the influence of flowering delay on total biomass accumulation could be obtained either by monitoring growth rates from video-imaging (Leister et al, 1999) or

Table 2 Comparison between the two reciprocal forms in generations $\mathrm{F}_{1}$ and $\mathrm{F}_{2}$ for six traits in five hybrids of $A$. thaliana

\begin{tabular}{|c|c|c|c|c|c|c|}
\hline \multirow[t]{2}{*}{ Trait } & \multirow[t]{2}{*}{ Generation } & \multicolumn{5}{|c|}{ Hybrid } \\
\hline & & $\mathrm{C} 24^{a} \times \mathrm{Aa}-\mathrm{O}^{b}$ & $\mathrm{C} 24^{a} \times W s-2^{b}$ & Ws $-2^{a} \times$ Col- $0^{b}$ & Col- $0^{a} \times C 24^{b}$ & Col-0 $0^{a} \times$ Wei- $0^{b}$ \\
\hline \multirow[t]{2}{*}{ Flowering date (days) } & $\mathrm{F}_{1}$ & 8.7 & 1.3 & -0.2 & -2.8 & 0.7 \\
\hline & $\mathrm{F}_{2}$ & -0.9 & 1.7 & 0.6 & 7.6 & -0.8 \\
\hline \multirow[t]{2}{*}{ Rosette diameter $(\mathrm{cm})$} & $\mathrm{F}_{1}$ & 1.06 & 1.34 & -0.82 & 0.63 & 0.51 \\
\hline & $\mathrm{F}_{2}$ & 0.22 & 1.74 & 0.42 & 1.45 & 1.08 \\
\hline \multirow[t]{2}{*}{ Biomass yield (g per 10 plants) } & $\mathrm{F}_{1}$ & 0.70 & $3.21^{* *}$ & -0.36 & $2.56^{*}$ & -0.50 \\
\hline & $\mathrm{F}_{2}$ & 0.60 & $2.98^{*}$ & $2.53^{*}$ & -0.78 & 2.24 \\
\hline \multirow[t]{2}{*}{ Seed yield (g per 10 plants) } & $\mathrm{F}_{1}$ & $-0.89^{*}$ & 0.60 & -0.16 & 0.40 & -0.27 \\
\hline & $\mathrm{F}_{2}$ & 0.23 & 0.21 & 0.47 & -0.62 & $0.91^{*}$ \\
\hline \multirow[t]{2}{*}{ 1000-seed weight (mg) } & $\mathrm{F}_{1}$ & -0.3 & 2.8 & -0.5 & -2.0 & -0.3 \\
\hline & $\mathrm{F}_{2}$ & -1.5 & -0.8 & 1.8 & 0.0 & -1.0 \\
\hline \multirow{2}{*}{ No. of seeds per plant $\left(10^{3}\right)$} & $\mathrm{F}_{1}$ & -3.96 & -1.08 & -1.60 & 4.36 & -2.19 \\
\hline & $\mathrm{F}_{2}$ & 2.67 & 1.97 & 1.08 & -3.16 & 5.28 \\
\hline
\end{tabular}

*,** Significant at $P=0.05$ and 0.01 , respectively, using a protected LSD.

${ }^{\mathrm{a}, \mathrm{b}}=\mathrm{P} 1, \mathrm{P} 2$, respectively. 
by determining biomass yield before the start of the generative phase.

From an agronomic point of view, biomass and seed yield are the most important traits with regard to heterotic response. Rosette diameter reflects biomass accumulation at an early stage and could serve as a supple-mentary trait for the vegetative part of the life cycle. The heterosis estimates reported in literature were rather low compared to the results in Table 1. For rosette diameter, El Asmi (1975) found an MPH of $18 \%$ compared to our $49 \%$. Pigliucci and Hayden (2001) even found smaller rosettes in their hybrids compared to the parents. Westerman (1971) reported 4\% MPH for leaf number as a measure for biomass heterosis. Griffing and Langridge (1963) found 23\% MPH for fresh weight, compared to our $60 \%$ increase for biomass yield. In particular, the hybrids Col- $0 \times$ C24 (60\%) and C24 × Aa-0 $(140 \%)$ can be recommended for investigations into the underlying causes of heterosis for biomass yield. In this context, it should also be of interest to include measurements of the root system, which might explain a substantial proportion of heterosis in biomass and seed yield by an increased efficiency of nutrient uptake. More detailed information on the physiological causes of heterosis for biomass yield could be gathered by comparing $F_{1}$ hybrids and their parents for the rate of cell division, cell size, photosynthesis rate, and the metabolic flux of sugars, proteins, or other metabolites, which have been suggested as an explanation for heterosis (de Vienne et al, 2000).

For seed yield, we found unexpectedly high positive MPH values for two hybrids (20\% for hybrid Ws- $2 \times$ Col0 and $65 \%$ for hybrid Col- $0 \times$ Wei- 0 ). In agreement with our results, Alonso-Blanco et al (1999) reported 24\% MPH in the number of seeds per plant in hybrid Ler $\times$ Cvi. However, heterosis for this trait can be much higher in suitable parent matches such as hybrid Col- $0 \times$ Wei- 0 . The positive MPH for seed yield is attributable to an increased 1000-seed weight $(\mathrm{C} 24 \times \mathrm{Aa}-0)$ or an increased number of seeds per plant $(\mathrm{Col}-0 \times$ Wei- 0 and Ws- $2 \times$ Col-0). While factors for yield components together with multiplication effects can explain heterosis for seed yield (Schnell and Cockerham, 1992; Melchinger et al, 1994), experimental procedures for measuring yield components are considerably more cumbersome and prone to errors in Arabidopsis than in small grains or maize.

Hybrid Col- $0 \times \mathrm{C} 24$ was unusual because of its markedly lower seed yield in combination with a substantial increase in biomass, indicating that increased vigour because of heterosis can be manifested in different ways depending on the particular genomic constitution. Viewed under the microscope, the $F_{1}$ seeds from this hybrid already had rather heterogeneous size with numerous shrunken or oversized seeds suggesting reduced fertility (S Barth, unpublished results). Thus, unintentional selection cannot be ruled out when investigating the viable plants from this stock. Similar observations were reported for wide crosses between $A$. thaliana and A. lyrata, where numerous malformed pollen grains were found (Nasrallah et al, 2000). Comparable to hybrid $\mathrm{Col}-0 \times \mathrm{C} 24$ in our study, these researchers found heterosis of biomass for both rosette diameter and root system in combination with reduced fertility.
Our study reveals little information about the genetic effects underlying the observed heterosis. We were not able to separate additive and dominance effects from various types of epistatic effects by a generation means analysis (Mather and Jinks, 1982), because, in addition to the parents, only the $F_{1}$ and $F_{2}$ generations were evaluated. However, since the test for NLID was nonsignificant in all instances, we conclude that epistasis was either absent or additive and any dominance type of epistatic effects were of opposite sign and cancelled each other out in the sum.

\section{Reciprocal effects}

We found significant reciprocal differences for biomass and seed yield (Table 2), but no consistent pattern was found across hybrids and parents. This inconsistency of our results could be attributable to seed production via emasculated flowers, which deteriorates the viability of the resulting seed stock in comparison to natural self-fertilization. Another cause could be maternal effects (Crane and Nyquist, 1967; Alonso-Blanco et al, 1999; Nasrallah et al, 2000). Since growth of $F_{1}$ seeds depends on the genetic or nutritional condition of the seed parent, reciprocal effects from this source are plausible, but should differ between $\mathrm{F}_{1}$ and $\mathrm{F}_{2}$ seeds. Reciprocal effects disappearing in $\mathrm{F}_{2}$ were detected in $\mathrm{C} 24 \times \mathrm{Aa}-0$ and $\mathrm{Col}-0 \times \mathrm{C} 24$ in agreement with earlier reports on other hybrids (Corey et al, 1976; Alonso-Blanco et al, 1999). Only for hybrid $\mathrm{C} 24 \times$ Ws-2 did the reciprocal effect persist across both generations and this cannot be attributed to unintentional selection for vigour during sowing and planting. Since reciprocal effects cannot be ruled out entirely in crosses with Arabidopsis, it seems prudent to standardize the growing conditions to the utmost extent and use the same seed parent and production scheme for the materials to be compared. Potential effects from seed production in emasculated flowers could be avoided by use of male sterile seed parents for both parents and hybrids, or by seed multiplication of lines from emasculated flowers.

\section{Genetic distance and heterosis}

If positive dominance effects are the primary cause of heterosis, a quadratic relation between heterosis and genetic distance is expected (Falconer and Mackay, 1996). An optimum distance has been postulated, beyond which hybrid performance declines due to a lack of adaptation between divergent genomes (Moll et al, 1965). The negative association between AMPH and GD for flowering date, rosette diameter, biomass yield, and 1000-seed weight was mostly attributable to atypical results for hybrid C24 $\times$ Aa-0, which showed a high performance level despite its low parental GD (Figure 1). For a more comprehensive analysis of the correlation between GD and AMPH, a larger number of hybrids with diverse GD values should be evaluated in order to examine whether our results are representative for Arabidopsis in general. Moreover, a tighter relation between GD and AMPH is expected if GD is determined with molecular markers linked to QTLs underlying the trait rather than molecular markers covering the entire genome (Charcosset and Essioux, 1994). 
Arabidopsis: a model system to study the molecular causes of heterosis

Since heterosis is a general phenomenon in the entire plant kingdom, a promising approach is to investigate its molecular basis in a model species and verify the hypotheses and results in other species of economic interest. Ideally, the model species should meet the following criteria: (1) sufficient amount of heterosis for traits of agronomic interest, (2) ease of experimental use in large-scale experiments, and (3) well-developed genomic tools. With a proper choice of hybrids and concentration on traits related to vigour, our results demonstrated that Arabidopsis is an excellent tool that matches all these requirements. Its low growth requirements and short life cycle are additional advantages. Obviously, accurate evaluation of the traits and proper statistical analysis require repeated experiments under controlled conditions. In spite of working in a greenhouse, the experimental variation between replicated entries was substantial in our study. A total of 40 plants (four replications $\times$ five plants $\times$ two reciprocal forms or duplicate entries) per experimental unit seems to be at the lower end of the scale for accurate measurement of quantitative traits. Hence, increasing the number of replications and plants per entry is highly recommended for future experiments.

Investigation of heterosis could be pursued by QTL analyses in large populations, expression studies, or by metabolite monitoring. Available high-density maps and a possibility of generating any desired number of molecular markers from the full genomic sequence of ecotype Col-0 (The Arabidopsis Genome Initiative, 2000) make Arabidopsis at this time the most suitable system for this task. Numerous single nucleotide polymorphism (SNP) markers were developed (Cho et al, 1999), which can be utilized for dissection of QTLs affecting heterosis. In crops, maize would also be very attractive for heterosis studies because of its large heterotic response and the well-established tools in genetics and genomics. However, comparable experiments with maize would have excessive demands for field trials. Therefore, the resources for a research initiative on the molecular basis of heterosis in plants are put to best use, if results gathered in experiments with Arabidopsis are corroborated for agronomically important crops such as maize.

\section{Acknowledgements}

We gratefully acknowledge the expert technical assistance of Mrs Beate Devezi-Savula and Mrs Kristen Davies, and appreciate the support of Professor Dr Drhc Steiner and Dr Anvari for kindly giving us access to their lab equipment. AKB was supported by a fellowship from Katholischer Akademischer Ausländer-Dienst (KAAD). We are grateful for the suggestions of two anonymous reviewers, which improved the quality of the manuscript. This paper is dedicated to Professor Dr Drhc FW Schnell on the occasion of his 90th birthday, whose enthusiasm for the phenomenon of heterosis inspired our research.

\section{References}

Abbott RJ, Gomes MF (1989). Population genetic structure and outcrossing rate of Arabidopsis thaliana. Heredity 62: 411-418.
Alonso-Blanco C, Blankestijn-De Vries H, Hanhart CJ, Koornneef M (1999). Natural allelic variation at seed size loci in relation to other life history traits of Arabidopsis thaliana. Proc Natl Acad Sci 96: 4710-4716.

Barth S, Melchinger AE, Devezi-Savula B, Lübberstedt T (2000). A high-throughput system for genome-wide measurement of genetic recombination in Arabidopsis thaliana based on transgenic markers. Funct Integr Genom 1: 200-206.

Barth S, Melchinger AE, Lübberstedt T (2002). Genetic diversity in Arabidopsis thaliana L. Heynh. investigated by cleaved amplified polymorphic sequence (CAPS) and inter simple sequence repeat (ISSR) markers. Mol Ecol 11: 495-505.

Becker HC (1993). Pflanzenzüchtung. Eugen Ulmer Verlag: Stuttgart.

Charcosset AB, Essioux L (1994). The effect of population structure on the relationship between heterosis and heterozygosity at marker loci. Theor Appl Genet 89: 336-343.

Cho RJ, Mindrinos M, Richards DR, Sapolsky RJ, Anderson M, Drenkard E et al (1999). Genome-wide mapping with qbiallelic markers in Arabidopsis thaliana. Nat Genet 23 203-207.

Corey LA, Matzinger DF, Cockerham CC (1976). Maternal and reciprocal effects on seedling characters in Arabidopsis thaliana (L.) Heynh. Genetics 82: 677-683.

Crane PL, Nyquist WE (1967). Effects of different genecytoplasm systems on quantitative characters in reciprocal $\mathrm{F}_{2}$ crosses of maize (Zea mays L.) Crop Sci 7: 376-378.

de Vienne D, Damerval C, Leonardi A, Bost B, Piégu B, Dillmann C et al (2000). Genetics of the maize proteome. In: Gustafson JP (ed) Genomes, 22nd Stadler Genetics Symposium, Kluwer Academic/Plenum Publishers: New York. pp 123-139.

East EM (1908). Inbreeding in corn. Reports of the Connecticut agricultural experiment station for years 1907-1908, pp 419-428.

El Asmi H (1975). Further analysis of heterosis and its expression for the rosette diameter length in Arabidopsis thaliana (L.) Heynh. Arabidopsis Inf Serv 12. p. 24

Falconer DS, Mackay TFC (1996). Introduction to Quantitative Genetics, 4th edn. Longman: Harlow.

Griffing B, Langridge J (1963). Phenotypic stability of growth in the self-fertilized species. Arabidopsis thaliana. In: Hanson WD, Robinson HF (eds) Statistical Genetics and Plant Breeding, National Research Council: Washington, DC. pp 368-394.

Lamkey KR, Edwards JW (1999). The quantitative genetics of heterosis. In: Coors JG and Pandey S (eds) The Genetics and Exploitation of Heterosis in Crops, CCSA, ASA, and SSA: Madison, WI, USA. pp 31-48.

Leister D, Varotto C, Pesaresi P, Niwergall A, Salamini F (1999). Large-scale evaluation of plant growth in Arabidopsis thaliana by non-invasive image analysis. Plant Physiol Biochem 37: 671-678.

Li SL, Rédei GP (1969). Direct evidence for models of heterosis provided by mutants of Arabidopsis blocked in the thiamine pathway. Theor Appl Genet 39: 68-72.

Martin JM, Talbert LE, Lanning SP, Blake NK (1995) Hybrid performance in wheat as related to parental diversity. Crop Sci 35: 104-108.

Mather K, Jinks JL (1982). Biometrical Genetics: The Study of Continuous Variation, 3rd edn. Chapman \& Hall: London.

Melchinger AE (1999). Genetic diversity and heterosis. In: Coors JG and Pandey S (eds) The Genetics and Exploitation of Heterosis in Crops, CCSA, ASA, and SSA: Madison, WI, USA. pp 99-118.

Melchinger AE, Gumber RK (1998). Overview of heterosis and heterotic groups in agronomic crops. In: Concepts and Breeding of Heterosis in Crop Plants. CCSA special publication no. 25 , CSSA: Madison, WI, USA. pp 29-44.

Melchinger AE, Singh M, Link W, Utz HF, Kittlitz EV (1994). Heterosis and gene effects of multiplicative characters: theoretical relationships and experimental results from Vicia faba L. Theor Appl Genet 88: 343-348. 
Mitchell-Olds T (1995). Interval mapping of viability loci causing heterosis in Arabidopsis. Genetics 140: 1105-1109.

Moll RH, Lonnquist JH, Fortuna JV, Johnson CE (1965). The relationship of heterosis and genetic divergence in maize. Genetics 52: 139-144.

Moll RH, Salhuana WS, Robinson HF (1962). Heterosis and genetic diversity in variety crosses of maize. Crop Sci 2: 197-198.

Narang RA, Altmann T (2001). Phosphate acquisition heterosis in Arabidopsis thaliana: a morphological and physiological analysis. Plant Soil 234: 91-97.

Nasrallah ME, Yogeeswaran K, Snyder S, Nasrallah JB (2000). Arabidopsis species hybrids in the study of species differences and evolution of amphiploidy in plants. Plant Physiol 124: 1605-1614.

Nei M, Li WH (1979). Mathematical model for studying genetic variation in terms of restriction endonucleases. Proc Natl Acad Sci 79: 5269-5273.

Pigliucci M, Hayden K (2001). Phenotypic plasticity is the major determinant of changes in phenotypic integration in Arabidopsis. New Phytol 152: 419-430.

Schnell FW (1982). A synoptic study of the methods and categories of plant breeding. Zeitschr Pflanzenzüchtg 89: 1-18.

Schnell FW, Cockerham CC (1992). Multiplicative vs. arbitrary gene action in heterosis. Genetics 131: 461-469.
Shull GH (1908). The composition of a field of maize. Am Breed Assoc 4: 296-301.

Shull GH (1914). Duplicate genes for capsule form in Bursa bursa pastoris. Zeitschr indukt Abstammungs- und Vererbungslehre 12: 97-149.

Snedecor GW, Cochran WG (1980). Statistical Methods, 7th edn. Iowa State University Press: Ames, USA.

Somerville C, Somerville S (1999). Plant functional genomics. Science 285: 380-383.

The Arabidopsis Genome Initiative (2000). Analysis of the genome sequence of the flowering plant Arabidopsis thaliana. Nature 408: 796-815.

The Multinational Arabidopsis Steering Committee (2002). The multinational coordinated Arabidopsis thaliana functional genomics project: beyond the whole genome sequence. http://www.nsf.gov/pubsys/ods/getpub.cfm?bio0202.

Utz HF (1999). PLABSTAT. A computer program for statistical analysis of plant breeding experiments. Version $2 \mathrm{~F}$, University of Hohenheim.

Virmani SS (1996). Hybrid rice. Adv Agron 57: 377-462.

Westerman JM (1971). Genotype-environment interaction and developmental regulation in Arabidopsis thaliana. III. Inbred lines; analysis of response to photoperiod. Heredity 26: 373-382. 